\title{
FORMAÇÃO DE PROFESSORES PARA O ENSINO DE LUTAS NA EDUCAÇÃO FÍSICA ESCOLAR: O ESTADO DA QUESTÃO
}

\author{
FORMACIÓN DEL PROFESORADO PARA LA ENSEÑANZA DE LAS LUCHAS EN \\ LA EDUCACIÓN FÍSICA ESCOLAR: EL ESTADO DE LA CUESTIÓN
}

\section{TEACHER EDUCATION FOR TEACHING WRESTLING IN PHYSICAL EDUCATION AT SCHOOL: THE STATUS OF THE QUESTION}

\author{
Leandro Nascimento BORGES ${ }^{1}$ \\ Maria Petrília Rocha FERNANDES ${ }^{2}$ \\ Mabel Dantas Noronha CISNE ${ }^{3}$ \\ Heraldo Simões FERREIRA ${ }^{4}$
}

RESUMO: Este artigo tem por finalidade estabelecer um quadro analítico de estudos relacionados à temática acerca do ensino das lutas na Educação Física escolar. A metodologia utilizada foi a pesquisa qualitativa, a partir do levantamento bibliográfico, denominado "estado da questão", por meio da catalogação, tabulação e análise de dados obtidos nos títulos, resumos, e metodologia de artigos científicos. Como resultado, a pesquisa apontou para o distanciamento das discussões sobre lutas na formação em Educação Física, e acerca da necessidade de uma formação no âmbito das lutas na Educação Física escolar, tendo em vista que neste componente curricular, o esporte ainda é priorizado em detrimento dos outros conteúdos. Confirmamos, portanto, a significância e premência de debates sobre as lutas na Educação Física escolar. Em especial, no que diz respeito à formação continuada e prática pedagógica dos professores inseridos nas instituições de educação básica.

PALAVRAS-CHAVE: Educação física. Formação de professores. Lutas.

RESUMEN: Este artículo tiene como objetivo establecer un marco analitico de estudios relacionados con el tema de la enseñanza de las luchas en la Educación Física escolar. La metodología utilizada fue la investigación cualitativa, mediante el relevamiento bibliográfico, denominado "estado de la cuestión", mediante la catalogación, tabulación y análisis de los datos obtenidos en los títulos, resúmenes y metodología de los artículos científicos. Como

\footnotetext{
${ }^{1}$ Universidade Estadual do Ceará (UECE), Fortaleza - CE - Brasil. Mestrando no Programa de Pós-Graduação em Educação. Integrante do Grupo de Estudos e Pesquisas em Educação Física Escolar (GEPEFE/UECE). ORCID: https://orcid.org/0000-0001-8592-0436. E-mail: leandronborges@gmail.com

${ }^{2}$ Universidade Estadual do Ceará (UECE), Fortaleza - CE - Brasil. Doutoranda no Programa de Pós-Graduação em Educação. Integrante do Grupo de Estudos e Pesquisas em Educação Física Escolar (GEPEFE/UECE). ORCID: https://orcid.org/0000-0001-9965-639X. E-mail: petrilia@hotmail.com

${ }^{3}$ Universidade Estadual do Ceará (UECE), Fortaleza - CE - Brasil. Mestranda no Programa de Pós-Graduação em Educação. Integrante do Grupo de Estudos e Pesquisas em Educação Física Escolar (GEPEFE/UECE). ORCID: https://orcid.org/0000-0003-2371-1983. E-mail: mabeldantas12@gmail.com

${ }^{4}$ Universidade Estadual do Ceará (UECE), Fortaleza - CE - Brasil. Professor Adjunto e Professor Permanente no Programa de Pós-Graduação em Educação. Doutorado em Saúde Coletiva (UECE). Coordenador do Grupo de Estudos e Pesquisas em Educação Física Escolar (GEPEFE/UECE). ORCID: https://orcid.org/0000-00031999-7982. E-mail: heraldosimoes@uece.br
} 
resultado, la investigación señaló el alejamiento de las discusiones sobre las luchas en la formación de la Educación Física, y sobre la necesidad de la formación en el contexto de las luchas en la Educación Física escolar, considerando que en este componente curricular, el deporte aún se prioriza otros contenidos a expensas de la educación fisica. Confirmamos, por tanto, la trascendencia y urgencia de los debates sobre las luchas en la Educación Física escolar. En particular, en lo que respecta a la formación continua y la práctica pedagógica de los docentes que trabajan en las instituciones de educación básica.

PALABRAS CLAVE: Educación Física. Formación del profesorado. Luchas.

ABSTRACT: This article aims to establish an analytical framework of studies related to the theme about the teaching of fights in school Physical Education. The methodology used was qualitative research, based on a bibliographic survey, called "state of the question", through cataloging, tabulation, and analysis of data obtained from the titles, abstracts, and methodology of scientific articles. As a result, the research pointed to the distance of the discussions about fights in Physical Education education, and about the need for a training on fights in school Physical Education, considering that in this curricular component, sport is still prioritized to the detriment of other contents. Therefore, we confirm the significance and urgency of debates about fights in school Physical Education. In particular, with regard to continuing education and pedagogical practice of teachers inserted in basic education institutions.

KEYWORDS: Physical education. Teacher education. Wrestling.

\section{Introdução}

A pesquisa traz um quadro analítico de produções acadêmicas sobre a temática do ensino de lutas na Educação Física escolar, evidenciando algumas problemáticas na formação dos professores de Educação Física para o desenvolvimento deste conteúdo de ensino.

Parte-se da problemática de que existe uma lacuna nos currículos das formações em Educação Física das instituições de curso superior, acerca da temática da formação de professores para o ensino das lutas na escola. O ensino das lutas é assegurado em termos de diretrizes curriculares, mas tende a ser um conteúdo pouco abordado por muitos cursos de formação superior na Educação Física, o que repercute em problemas para sua efetivação no âmbito escolar (RUFINO; DARIDO, 2015).

Corrobora-se com Neira (2008), ao afirmar que as práticas corporais, os movimentos, são formas de explorar o corpo e suas possibilidades, proporcionando a percepção corporal a partir desta prática, contribuindo para a formação do indivíduo, valorizando seus conhecimentos, seus costumes, visando à promoção de atitudes de respeito e da igualdade social. Dessa forma, a formação profíssional no âmbito da Educação Física deve contemplar o 
universo das práticas corporais, incluindo o ensino das lutas, buscando contribuir com a formação e a ampliação do conhecimento das lutas como manifestação da cultura corporal de movimento.

Destarte, acerca do componente curricular Educação Física, destaca-se que em 1992, no livro Metodologia do Ensino da Educação Física, uma produção com abordagem crítica advinda do materialismo histórico dialético, surge uma das primeiras propostas de conteúdo para a Educação Física na escola. Também conhecido como Coletivo de Autores, a referida obra possibilitou uma perspectiva crítica para trabalhar os conteúdos durante as aulas através de suas sugestões direcionadas à classe popular, concebendo assim uma abordagem críticosuperadora, surgindo a cultura corporal como objeto a ser estudado pela Educação Física (SOARES et al., 1992).

Os conteúdos propostos pelo livro, que se tornou uma referência para os professores da época, foram: jogos, esportes, ginásticas, dança e capoeira. Pela primeira vez se apontava, dentre o leque de opções para o ensino, uma luta, no caso, a capoeira. Esta se inseria como uma espécie de reconhecimento de uma cultura corporal brasileira. Assim, considerando a atual diversidade dos conteúdos, daremos ênfase, neste projeto em nível de mestrado, ao conteúdo lutas.

Em 1997, foram elaborados os Parâmetros Curriculares Nacionais - PCN (BRASIL, 1997), com a finalidade de sugerir aos professores orientações a partir de blocos de conteúdo, permitindo uma diversidade de possibilidades para o trabalho com a Educação Física escolar. O referido documento, norteador, não obrigatório na Educação Básica, apresentava os seguintes conteúdos: conhecimento sobre o corpo; atividades rítmicas e expressivas; esportes, jogos, lutas e ginásticas. Novamente, o conteúdo lutas foi salientado em um documento relevante à área da Educação Física. É crucial ressaltarmos que este documento imprimiu legalidade às práticas pedagógicas do professor de Educação Física, baseando-se na realidade do cotidiano dos alunos.

Concomitante à essa expansão e reconhecimento em âmbito nacional e internacional, observa-se que mesmo fazendo parte do currículo da Educação Física da Educação Básica, o conteúdo Lutas ainda é pouco explorado no cotidiano escolar, seja pela falta de domínio dos processos didático-metodológicos dessas práticas corporais por parte do professor, seja pelo currículo da disciplina que tem o Esporte como conteúdo hegemônico.

No que se refere a esta temática, Oliveira e Reis filho (2013) assinala que existem alguns problemas que inviabilizam a vivência desta prática corporal nas aulas de Educação Física, tais como: preconceito com as lutas, nutrido pela errônea percepção de que o ensino de 
uma modalidade de combate poderá estimular o aluno à agressividade; escassez de material e infraestrutura: uniformes apropriados, conforme a prática planejada pelo professor, e pisos acolchoados

Em pesquisa realizada por Ferreira (2009), constatou-se que $68 \%$ dos profissionais que não utilizavam lutas nas aulas de Educação Física eram motivados pela falta de instrução para lecionar tal atividade, o que ratifica a relação de existência entre o saber fazer e o fazer. Acredita-se que aos professores de Educação Física cabe implementar os diversos temas de ensino, quais sejam: jogos, brincadeiras, esportes, lutas, danças, ginásticas, práticas corporais de aventura, oportunizando experiências diversificadas aos estudantes, desenvolvendo sua autonomia e sua criatividade, estimulando-os a participarem em contextos de saúde e lazer (BRASIL, 2017).

Diante dos dados apresentados e da pouca inserção das lutas no âmbito escolar, compreendemos os fatos e reconhecemos a fragilidade na temática da formação de professores para o ensino das lutas na escola, partindo do seguinte questionamento: uma formação em Lutas brasileiras para professores de Educação Física, que não tiveram experiências extra-acadêmicas e pessoal com lutas, poderá ser resolutiva para sua intervenção na prática pedagógica desta unidade temática em suas aulas, na Educação Básica? Esta inquietação adveio do entendimento de que constituir-se professor faz parte de um movimento, de uma caminhada de reflexões e da forma como mobiliza os conhecimentos que fazem parte de seu repertório de saberes, na busca da resolução dos desafios que se apresentam na sua prática educativa, para uma tomada de decisão consciente e intencional (SACRISTÁN, 1999).

Diante desses desafios, surge o desejo de conhecermos produções que abordassem esse tema. Intentamos a realização de um movimento de saída do nosso olhar para conhecer outras perspectivas acerca da temática, que permitisse a compreensão do movimento da área de conhecimento, suas configurações, propensões teóricas e metodológicas, análises críticas, recorrências e lacunas. Assim, compreendemos que, para evidenciar as contribuições do que nos propomos a investigar para o campo do conhecimento, se faz necessária essa investigação denominada Estado da Questão (EQ) sobre o objeto de pesquisa por meio de um inventário da produção científica acerca do tema. Esse percurso tem como escopo a definição descrita por Nóbrega-Therrien e Therrien (2010, p. 36), na qual afirmam que o EQ:

[...] é uma maneira que o estudante/pesquisador pode utilizar para entender e conduzir o processo de elaboração de sua monografia, dissertação ou tese, ou seja, de produção científica com relação ao desenvolvimento de seu tema, 
objeto de sua investigação. É um modo particular de entender, articular e apresentar determinadas questões mais diretamente ligadas ao tema ora em investigação.

Para Nóbrega-Therrien e Therrien (2004), o pesquisador alcança o domínio da literatura quando ele é capaz de investigar uma extensiva e relevante literatura e ao mesmo tempo utilizá-la no desenvolvimento de análise e discussão de ideias; enquanto o domínio conceptual é alcançado quando há capacidade de organizar com coerência, perspectivas ou teorias relevantes para interpretar e explorar seu tema de estudo e acrescentar a este uma análise crítica.

Ao utilizar-se a metodologia do Estado da Questão, faz-se com que o material encontrado seja confrontado com a proposta de investigação a ser desenvolvida, havendo um diálogo entre o pesquisador e a produção científica encontrada (SILVEIRA; NÓBREGATHERRIEN, 2011).

Para o trato metodológico do Estado da Questão, recorreu-se, inicialmente, a diálogos com o orientador, e após indicação do mesmo, deu-se início a estudos em uma disciplina ofertada no curso do Programa de Pós-graduação em Educação - PPGE pela Universidade Estadual do Ceará. A disciplina tem como foco discutir sobre a importância de entender e encaminhar o processo de produção científica pelo estudante/pesquisador, com relação à elaboração do Estado da Questão sobre seu tema, objeto de investigação.

Dito isso, destacamos que a análise do EQ requer tempo e disponibilidade ao pesquisador, pois conforme o descritor utilizado para a pesquisa, este poderá indicar, entre outras hipóteses, que ainda não há uma publicação significativa no periódico pesquisado sobre a temática em foco.

\section{Procedimento metodológico}

A metodologia utilizada contemplou uma pesquisa qualitativa do tipo bibliográfica, que nos permitiu encontrar o referencial teórico adequado para o desenvolvimento desta discussão. A pesquisa bibliográfica corresponde a uma análise a livros, artigos, teses, anais de congressos, material da internet entre outros. Embora em quase todos os trabalhos sejam exigidos uma base teórica, para uma pesquisa ser considerada puramente bibliográfica, esta deve ser feita exclusivamente em materiais teóricos e documental (GIL, 2002).

A fonte de dados utilizada foi a plataforma de pesquisa da Coordenação de Aperfeiçoamento de Pessoal de Nível Superior - CAPES, direcionando a busca para o portal 
de periódicos da mesma plataforma. O portal possui um dos maiores acervos de revistas virtuais do mundo, garantindo uma confiabilidade renomada em todo o país. A escolha justifica-se pela facilidade de acesso ao sítio às diversas áreas de pesquisa, pois a disponibilidade vem em modo digital, democratizando, assim, todo o acesso. As buscas aconteceram no período de setembro de 2020 a novembro do mesmo ano, utilizando opções de refinamento, tal como revisado por pares e apenas com idioma em português.

Delimitamos, como recorte temporal, os periódicos que contemplavam os anos de 1997 a 2019. A escolha dos anos dar-se em conta ao aparecimento do termo lutas na escola advindo dos PCN: Educação Física, publicado em 1997 (BRASIL, 1997). No que se refere aos periódicos, decidimos, para atingir um maior número de trabalhos, não fazer nenhuma delimitação de acordo com o sistema Qualis CAPES.

Inicialmente, a busca, na plataforma, foi realizada sem combinação e refinamento. Para efeito de informação acerca do trajeto metodológico específico das buscas, julgamos necessário a menção de que diversos descritores foram utilizados na tentativa de obter dados relevantes acerca do objeto de estudo. Todavia, não obtivemos êxito durante as buscas nos sítios decs.bvs.br e Thesaurus Brasileiro da Educação, site vinculado ao Instituto Nacional de Estudos e Pesquisa Educacionais Anísio Teixeira -INEP.

Dentre as categorias que descrevemos como descritores, no primeiro site citado, buscou-se por "Educação Física Escolar", contabilizando um total de zero descritor. Na categoria "Ensino de Lutas", obtivermos o mesmo resultado: zero descritores. Finalmente, na busca por "Formação Continuada", contabilizou 1 descritor.

Figura 1 - Caminho percorrido para a utilização dos descritores na plataforma de busca da Capes

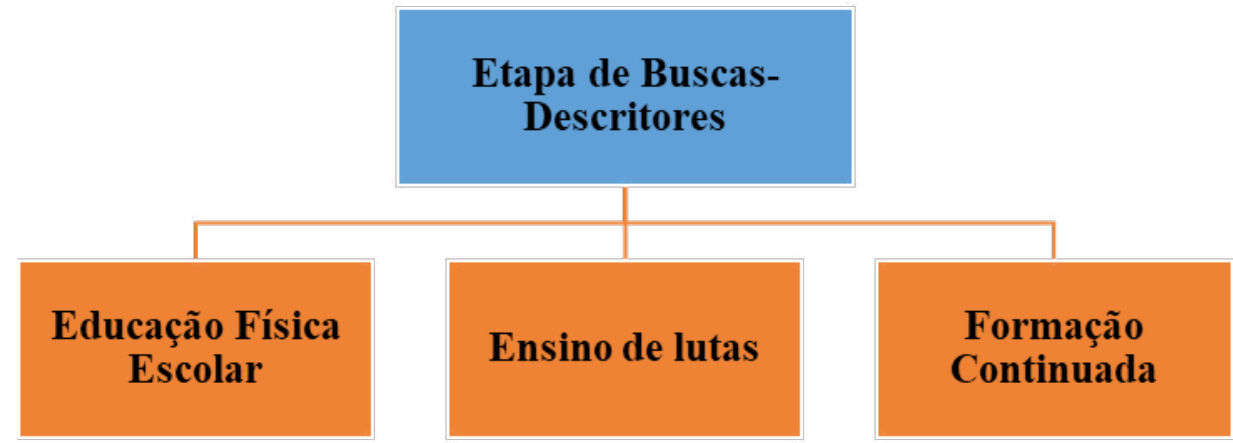

Fonte: Elaborado pelos autores 
No primeiro momento, logo após a escolha dos descritores, utilizamos os mesmos de forma combinatória entre eles. Na primeira busca, descrevemos Ensino de Lutas $A N D$ Educação Física Escolar, o qual gerou um número de 112 artigos em periódicos.

Quadro 1 - Relação dos descritores combinados "educação física escolar $A N D$ ensino de lutas" utilizados no EQ, 2 etapas

\begin{tabular}{|c|lr|rr|r|r|}
\hline Descritores & & & \\
& esultados & F & & \\
& iltrados & chados & \\
\hline "educação física escolar & & 16 & & 8 & 6 & 3 \\
AND ensino de lutas" & 0 & & &, 75 \\
\hline
\end{tabular}

Fonte: Elaborado pelos autores

Durante a combinação dos descritores, utilizamos o boleano $A N D$ e aspas, optamos por utilizar artigos apenas escritos em português, e para refinamento revisados por pares, a fim de encontrarmos, com precisão, artigos em periódicos que nos aproximassem mais do objeto de pesquisa. Portanto, ao inserir "educação física escolar $A N D$ ensino de lutas" pode-se constatar um total de 160 trabalhos. Após o filtro, realizado a partir da leitura do título, do resumo e da metodologia, este número reduziu para 81.

Então, através das buscas, compreendemos que, de 160 artigos encontrados nos periódicos mediante a busca na plataforma, 3,5\% correspondem às categorias que relacionamos à pesquisa proposta. Diante do quadro exposto, consideramos que o número reduzido de produções está relacionado à categoria, o que demonstra uma lacuna na produção acadêmica.

No segundo quadro, apresentaremos os achados a que correspondem os artigos que se aproximam do objeto de estudo, com seus respectivos autores e periódicos.

\section{Resultados e discussão}

A partir da análise das dissertações e teses selecionadas, os resultados evidenciaram um maior número de trabalhos publicados no ano de 2017 e realizados por pesquisadores de Universidades Públicas. Além disso, seis trouxeram informações sobre cursos de formação continuada elaborados. Os estudos e respectivos objetivos podem ser visualizados no quadro abaixo: 
Quadro 2 - Quadro quantitativo (descritivo) da distribuição dos achados por periódico, com análise das estatísticas

\begin{tabular}{|c|c|c|}
\hline Achados/Autor & Periódico & Título \\
\hline Rufino (2016a) & $\begin{array}{c}\text { Revista brasileira de } \\
\text { prescrição e fisiologia do exercício }\end{array}$ & $\begin{array}{lrrrr} & \text { As } & \text { lutas } & \text { no } & \text { contexto } \\
\text { escolar e } & \text { outros } & & \text { ambientes } \\
\text { educacionais } & & & & \end{array}$ \\
\hline Rufino (2016b) & $\begin{array}{cc}\text { Revista brasileira } & \text { de } \\
\text { prescrição e fisiologia do exercício } & \end{array}$ & $\begin{array}{l}\text { Fundamentos das lutas e } \\
\text { o processo de inclusão: perspectivas } \\
\text { pedagógicas na diversidade educativa } \\
\text { contemporânea }\end{array}$ \\
\hline Rufino e Darido & $\begin{array}{lll}\text { Física/UEM } & \text { Revista } & \text { Educação }\end{array}$ & $\begin{array}{l}\text { O ensino de lutas nas } \\
\text { aulas de educação física: análise da } \\
\text { prática pedagógica à luz de } \\
\text { especialistas }\end{array}$ \\
\hline al. (2014) Mazini Filho et & CINERGIS & $\begin{array}{l}\text { O ensino de Lutas nas } \\
\text { aulas de educação física escolar }\end{array}$ \\
\hline Rufino (2016c) & $\begin{array}{c}\text { Revista brasileira de } \\
\text { prescrição e fisiologia do exercício }\end{array}$ & $\begin{array}{l}\text { Os jogos de lutas nas } \\
\text { aulas de educação física escolar: } \\
\text { possibilidades técnico-táticas e seus } \\
\text { elementos variantes }\end{array}$ \\
\hline $\begin{array}{c}\text { Hegele, } \\
\text { González e Borges (2018) }\end{array}$ & $\begin{array}{l}\text { Caderno de educação } \\
\text { física e esportes }\end{array}$ & $\begin{array}{l}\text { Possibilidades do ensino } \\
\text { das lutas na escola: uma pesquisa -ação } \\
\text { com professores de educação física }\end{array}$ \\
\hline
\end{tabular}

Fonte: Elaborado pelos autores.

A partir da leitura do material completo das seções referentes à introdução e aos resultados, buscou-se analisar: objetivo, resultados e conclusão dos referidos artigos destacados no quadro acima.

Para compreender os trabalhos direcionados à Educação Física escolar e ao ensino de lutas, destacamos uma análise dos artigos encontrados.

De início, começaremos nossa análise pelos estudos de Rufino (2016a), que teve como objetivo compreender e analisar as abordagens pedagógicas no que se refere ao desenvolvimento e ensino das lutas, partindo da análise crítica, buscando analisar, a partir das dificuldades dos aspectos sócio-históricos, as lutas em ambientes formais e não formais, como por exemplo escolas, academias, clubes, centros esportivos.

O autor destaca que compreendendo a pedagogia das lutas é possível aperfeiçoar sua prática pedagógica, embora o tradicionalismo ainda seja evidente em algumas abordagens. 
Destaca, ainda, um quadro comparativo e compartilha as dificuldades de trabalhar as lutas em contexto escolar, descrevendo, concomitantemente, as possibilidades para cada problema descrito.

O professor de Educação Física, a partir de sua formação pedagógica, reúne competências e habilidades para inserir em suas aulas elementos das lutas como: autonomia, criticidade, respeito, caráter, contribuindo assim com a formação integral do aluno. "Compreende-se que o trato pedagógico do componente lutas na Educação Física escolar deva comportar necessariamente aspectos da autonomia, criticidade, emancipação e a construção de conhecimentos significativos" (NASCIMENTO; ALMEIDA, 2007, p. 93).

No que se refere à metodologia utilizada, trata-se de um estudo descritivo, com revisão de literatura direcionada às lutas dentro e fora do ambiente escolar. Sendo assim, como resultados, Rufino (2016a) destacou as seguintes categorias: "preconceito, falta de matérias, formação inicial deficiente, falta de produção acadêmica", apresentando, para cada uma, dificuldades e possibilidades para a utilização das lutas na Educação Física escolar. Ressaltamos aqui que não contribui para este Estado da Questão descrever as lutas em âmbitos não formais, pois tal aspecto não se aproxima do intuito da pesquisa.

No segundo estudo encontrado, Rufino (2016b) ressalta a inclusão das lutas nas aulas de Educação Física, pois a insegurança em ministrar o conteúdo ocasiona uma resistência por parte dos docentes em trabalhar com esta temática. Neste artigo, o autor tem como objetivo analisar os fundamentos pedagógicos das lutas a partir dos processos de inclusão, propondo assim uma diversificação do trabalho com lutas. $\mathrm{O}$ método utilizado teve uma abordagem qualitativa descritiva, fundamentado em uma revisão de literatura, destacando como eixo centralizador a inclusão das lutas.

No que se refere à inclusão das lutas, o autor destaca que não direciona apenas a incluir alunos com deficiência, mas também os gêneros masculino e feminino, alunos com problemas de saúde, tal como obesidade e simpatizantes de práticas de lutas. O método utilizado pelo pesquisador consistiu em um estudo descritivo com revisão de literatura. Dessa forma, os resultados colaboraram para uma reflexão pertinente às lutas, dentre as citadas, ampliar as possibilidades de inclusão para todas as pessoas, propiciando as vivências e conhecimento. Depreende-se, deste modo, que as lutas possibilitam uma variedade de atividades, dentre elas, uma variação de pessoas, de peso, de alunos que treinam. A formação contínua contempla e urge com necessidade para professores que aderem utilizar as lutas como conteúdo, contribuindo para a compreensão do processo pedagógico e desmitificação de padrões e mitos sobre as lutas. 
O terceiro trabalho, de autoria de Rufino e Darido (2015), teve como objetivo analisar as opiniões de professores universitários, especialistas em lutas, direcionadas apenas para a prática pedagógica das lutas nas aulas de Educação Física escolar. Desta vez, o método vem como técnica de coleta de dados, ou seja, os autores utilizaram-se de uma entrevista semiestruturada que contou com participação de cinco professores especialistas em luta de maneira intencional. Rufino e Darido (2015) comentam sobre afinidade no discurso de três especialistas, que destacam a formação inicial do professor de Educação Física como ainda frágil para fazê-los sentir-se preparados para trabalhar com lutas na escola.

Diante dessas falas, atenta-se para a importância de que uma formação continuada poderá proporcionar aperfeiçoamento aos professores da Educação Básica, contemplando o conteúdo lutas de forma segura e pedagógica. Acerca da formação continuada, se pode compreender que:

Tanto a formação inicial quanto a formação continuada, agindo de maneira articulada, devem dar subsídios científicos para que o professor possa sentirse competente para recriar sua prática e atuar de maneira transformadora. Nesse sentido, a inclusão das Lutas no currículo real da Educação Física estabelece dependências com a formação dos professores em relação a esse conteúdo (BELTRÃO DE MATOS et al., 2015, p. 123).

Em sua pesquisa, Mazini Filho et al. (2014), tem como objetivo analisar como vem sendo abordada as lutas nas aulas de Educação Física em um município do estado de Minas Gerais à luz dos Parâmetros Curriculares Nacionais - PCN (BRASIL, 1997). Trata-se de uma pesquisa transversal que contou com 18 professores da rede municipal. $\mathrm{O}$ instrumento que cunha a coleta de dados, baseou-se em um questionário fechado, adaptado, com seis questões. Para o gerenciamento dos dados, utilizou-se frequência relativa e percentual nas questões propostas. Destacamos aqui este estudo, uma vez que se aproxima de nosso estudo, o qual terá como investigação as lacunas existentes para o ensino de lutas de professores de Educação Física escolar, tendo como norte os PNC (BRASIL, 1997).

Ferreira (2006) destaca que a utilização das lutas não se confunde com a tendência militarista, em que tal proposta tinha como pretensão preparar o indivíduo para o combate/guerra. Seu objetivo é proporcionar ao aluno uma diversidade mais ampla de vivências corporais por meio das experiências culturais. Mediante a dificuldade dos professores relatadas nos estudos apresentados, destacamos a relevância de uma formação continuada para que se possa romper com esses paradigmas, assim como inserir as lutas de forma segura e responsável, proporcionando ao aluno uma diversidade maior de vivências e 
atendendo os documentos que contemplam a Educação Básica, como por exemplo os PCN (BRASIL, 1997) e a BNCC (BRASIL, 2017; 2018).

Destarte, compreendemos que as lutas podem ir além da especificidade de cada arte, inserindo o lúdico em suas ações, apropriando-se do contexto em que o indivíduo está inserido e não centralizando apenas atividades técnicas propriamente ditas. Sobre isto, diz Rufino (2016c), em relação às proposições dos documentos de nível federal citados acima, que estes asseguram as lutas como trato pedagógico, e a ausência de uma análise crítica destes documentos corrobora para a escolha de esportes hegemônicos no Brasil, tais como o judô e a capoeira.

Em seu estudo, Rufino (2016c) propõe vivenciar uma diversidade de práticas envolvendo as lutas através de uma oficina teórico-prático, no qual pretendeu-se relatar o desenvolvimento do processo formativo lutas a partir da utilização dos jogos. Para a execução da formação, o autor utilizou-se de práticas metodológicas centradas na reflexão crítica, a saber: debates, atividades práticas dentro e fora de sala, análise crítica de situações problematizadoras e, por último, a criação de atividades explorando a autonomia dos participantes.

Seus resultados pautaram em reconhecer o lúdico como estratégia para inclusão de lutas, reconhecendo a técnica e tática alinhadas aos elementos que o autor chama de invariantes, sendo elas: alvo móvel, oposição direta entre indivíduos e enfrentamento físico (RUFINO; DARIDO, 2015).

Dentre os seis achados que a busca pôde fornecer através dos periódicos, a pesquisa de Hegele, Gonzalez e Borges (2018) contou com uma pesquisa-ação, a qual tive como participantes quatro professores da rede municipal do interior do estado do Rio Grande do Sul. Ressaltamos aqui o tipo de metodologia utilizada pelos autores: esta consistiu em perceber o impacto de uma formação colaborativa a professores que, por vezes, se sentiam inseguros ou não teriam vivenciado o conteúdo lutas na academia durante a graduação.

Como vimos, poucos trabalhos que pesquisam as lutas na escola utilizam como metodologia a pesquisa-ação $(n=5 ; 13 \%)$. Dessa forma, consideramos que o uso dessa metodologia dará à nossa pesquisa um caráter mais original, contribuindo para o avanço do conhecimento. Poucos estudos trazem contribuições para a região nordeste. Este é um diferencial de nossa pesquisa, por se propor a pesquisar esta temática que se mostra "tímida" no que se direciona à produção científica.

De acordo com Ferreira (2006), as práticas corporais de lutas devem ser expostas aos discentes nas escolas e centros universitários de Educação Física. A partir destas instituições, 
pode-se, ainda, ser aplicada a discussão para além das técnicas. Um dos temas que o autor sugere está pautado na violência, exacerbada por camadas da sociedade e pelo confronto entre torcidas de times de futebol.

Portanto, buscamos, com o inventariado das produções acadêmicas que abordam a temática do ensino de lutas na Educação Física escolar no período estabelecido, extrair informações que nos possibilitassem responder às nossas indagações, construindo, assim, um arcabouço acerca do conhecimento que vem sendo produzido sobre o tema no país.

\section{Considerações finais}

As bases de dados pesquisadas e o material investigado nos mostraram a quantidade reduzida de artigos que tratem diretamente sobre a formação de professores em Educação Física para o ensino de lutas na escola. Temos tido mais publicações acerca da educação permanente em saúde do que propriamente da política, contudo, fazem-se necessários outros debates e pesquisas, para que possibilitem diagnósticos, conhecimento e estratégias para a implementação desta em outras escolas brasileiras.

Com base nesta constatação, ansiamos que nosso texto possa contribuir para uma continuidade ao debate sobre o tema lutas na Educação Básica, possibilitando assim, uma reflexão aos/para e com os professores de Educação Física acerca do conteúdo lutas, tendo em vista que esta temática, ainda pouco explorada na escola, pode permitir uma diversidade de conteúdos a serem desenvolvidos nas aulas de Educação Física escolar, tais como: poderiam citar alguns exemplos.

Portanto, diante dos resultados que serão discutidos posteriormente, uma vez que este estudo que ora se apresenta é um recorte e está em desenvolvimento, a pesquisa em lutas corrobora para o fomento da ciência no campo da produção científica sobre a temática em questão. Desta forma, julgamos que a investigação realizada não encerra aqui tal discussão, mas a traz à baila alguns questionamentos, algumas problematizações, para juntos pensarmos na importância da sua implantação ou implementação.

\section{REFERÊNCIAS}

BELTRÃO DE MATOS, J. A. et al. A presença/ausência do conteúdo lutas na Educação Física Escolar: identificando desafios e propondo sugestões. Conexões: Revista da Faculdade de Educação Física da UNICAMP, Campinas (SP), v. 13, n. 2, p. 117-135, abr./jun. 2015. 
BRASIL. Ministério da Cidadania. Jogos Escolares Brasileiros-JEBS. 2020. Disponível em: http://arquivo.esporte.gov.br/index.php/institucional/o-ministerio/conselho-nacional-doesporte/162-ministerio-do-esporte/jogos-escolares-brasileiros/21722-jogos-escolaresbrasileiros-jeb-s. Acesso em: 23 jun. 2020.

BRASIL. Ministério da Educação. Base Nacional Comum Curricular (BNCC). Educação é a Base. Brasília, DF: MEC, 2017. Disponível em:

http://basenacionalcomum.mec.gov.br/images/BNCC_publicacao.pdf. Acesso em: 20 maio 2019.

BRASIL. Ministério da Saúde. Resolução n. 510, de 7 de abril de 2016. O Plenário do Conselho Nacional de Saúde em sua Quinquagésima Nona Reunião Extraordinária, realizada nos dias 06 e 07 de abril de 2016, no uso de suas competências regimentais e atribuições conferidas pela Lei n. 8.080, de 19 de setembro de 1990, pela Lei n. 8.142, de 28 de dezembro de 1990, pelo Decreto n. 5.839, de 11 de julho de 2006. Brasília, DF: Ministério da Saúde/Conselho Nacional de Saúde, 24 maio 2016. Disponível em: https://www.in.gov.br/materia/-/asset_publisher/Kujrw0TZC2Mb/content/id/22917581. Acesso em: 20 maio 2019.

BRASIL. Ministério da Educação. Lei n. 9.394, de 20 de dezembro de 1996. Lei de Diretrizes e Bases da Educação Nacional - LDB. Brasília, DF: MEC, 23 dez. 1996. Disponível em: http://www.planalto.gov.br/ccivil_03/leis/19394.htm. Acesso em: 20 maio 2019.

BRASIL. Secretaria de Educação Fundamental. Parâmetros curriculares nacionais: Educação Física. Brasília, DF: Secretaria de Educação Fundamental, 1997.

FERREIRA, H. S. As lutas na educação física escolar. Revista de Educação Física, Rio de Janeiro (RJ), v. 135, p. 23-45, 2006. Disponível em:

https://revistadeeducacaofisica.emnuvens.com.br/revista/article/view/428. Acesso em: 20 maio 2020.

FERREIRA, H. S. A utilização das lutas como conteúdo das aulas de Educação Física. Efdeportes, Buenos Aires, año 13, n. 130, mar. 2009.

GIL, A. C. Como elaborar projetos de pesquisa. 4. ed. São Paulo, SP: Atlas, 2002.

HEGELE, B.; GONZÁLEZ, F. J.; BORGES, R. M. Possibilidades do ensino das lutas na escola: uma pesquisa-ação com professores de educação física.Caderno de Educação Física e Esporte, Marechal Cândido Rondon (PR), v. 16, n. 1, p. 99-107, jan. 2018. Disponível em: http://e-revista.unioeste.br/index.php/cadernoedfisica/article/view/18953. Acesso em: 20 maio 2020.

MAZINI FILHO, M. L. et al. O ensino de lutas nas aulas de Educação Física Escolar. Cinergis, Santa Cruz do Sul (RS), v. 15, n. 4, p. 1-6, out./dez. 2014. Disponível em: https://online.unisc.br/seer/index.php/cinergis/article/view/5264. Acesso em: 30 jun. 2020.

NASCIMENTO, P. R. B; ALMEIDA, L. A tematização das lutas na Educação Física Escolar: restrições e possibilidades. Revista Movimento, Porto Alegre (RS), v. 13, n. 3, p. 91-110, 
2007. Disponível em: https://seer.ufrgs.br/Movimento/article/view/3567. Acesso em: 30 jun. 2020.

NEIRA, M. G. A cultura corporal popular como conteúdo do currículo multicultural da educação física. Revista Pensar a Prática, Goiânia (GO), v. 11, n. 1, p. 81-89, 2008. Disponível em: https://www.revistas.ufg.br/fef/article/view/1699. Acesso em: 30 jun. 2020.

NÓBREGA-THERRIEN, S. M.; THERRIEN, J. Trabalhos científicos e o estado da questão: reflexão teóricos-metodológicas, metodológicas. Estudos em Avaliação Educacional, São Paulo (SP), v. 15, n. 30, p. 5-16, 2004. Disponível em:

http://publicacoes.fcc.org.br/index.php/eae/article/view/2148. Acesso em: 30 jun. 2020.

NÓBREGA-THERRIEN, S. M; THERRIEN, J. O estado da questão: aportes teóricosmetodológicos e relatos de sua produção em trabalhos científicos. In: FARIAS, I. M. S. de; NUNES, J. B. C; NÓBREGA THERRIEN, S. M. (Org.). Pesquisa científica para iniciantes: caminhando no labirinto. Fortaleza: EdUECE, 2010. (Coleção Métodos de Pesquisa).

OLIVEIRA, S.B; REIS FILHO, A.D. Ensino de lutas na escola: elemento pedagógico ou estímulo à violência? Efdeportes.com. Buenos Aires - año 18, n.180, maio. 2013.

RUFINO, L. G. B. As lutas no contexto escolar e outros ambientes educacionais. Revista Brasileira de Prescrição e Fisiologia do Exercício, São Paulo (SP), v. 11, n. 11, p. 914-916, edição especial. 2016a.

RUFINO, L. G. B. Fundamentos das lutas e o processo de inclusão: perspectivas pedagógicas na diversidade educativa contemporânea. Revista Brasileira de Prescrição e Fisiologia do Exercício, São Paulo (SP), v. 63, n. 11, p. 919-920, out. 2016 b.

RUFINO, L. G. B. Os jogos de lutas nas aulas de educação física escolar: possibilidades técnico-táticas e seus elementos invariantes. Revista Brasileira de Prescrição e Fisiologia do Exercício, São Paulo (SP), v. 11, n. 63, p. 917-918, nov. 2016 c.

RUFINO, L. G. B; DARIDO, S. C. O ensino das lutas nas aulas de educação física: análise da prática pedagógica à luz de especialistas. Rev. Educ. Fís/uem, São Paulo (SP), v. 26, n. 4, p. 505-518, abr. 2015.

SACRISTÁN, J.G. Poderes instáveis em educação. Porto Alegre: Artmed, 1999.

SILVEIRA, C.S.; NÓBREGA-THERRIEN, S.M. Estudos sobre pesquisa e formação de professores da Educação Básica: a elaboração do Estado da Questão. Revista Educação em Questão, Natal, v. 41, n. 27, p. 219-243, jul./dez. 2011.

SOARES, C. L. et al. Metodologia do ensino de Educação Física. São Paulo, SP: Cortez, 1992. 


\section{Como referenciar este artigo}

NASCIMENTO, L. B.; FERNANDES, M. P. R.; CISNE, M. D. N.; FERREIRA, H. S. Formação de professores para o ensino de lutas na educação física escolar: o estado da questão. Revista Ibero-Americana de Estudos em Educação, Araraquara, v. 16, n. esp. 3, p. 1547-1561, jun. 2021. e-ISSN: 1982-5587. https://doi.org/10.21723/riaee.v16iesp.3.15297

Submissão em: 05/02/2021

Revisões requeridas em: 30/03/2021

Aprovado em: 12/05/2021

Publicado em: 01/06/2021

\section{CONTRIBUIÇÃO DOS AUTORES}

*Leandro Nascimento Borges: contribuiu com o delineamento da pesquisa; e com o processo de busca da base de dados, metodologia e conclusão.

*Maria Petrília Rocha Fernandes: contribuiu com a redação do manuscrito;

*Mabel Dantas Noronha Cisne: contribuiu com a categorização e análise dos trabalhos;

*Heraldo Simões Ferreira: contribuiu com a revisão crítica do trabalho. 